\title{
Characteristics of Obstructive Sleep Apnea Across the Spectrum of Glucose Tolerance in Obese Adolescents
}

\author{
Tamara S. Hannon ${ }^{1 *}$, Sara E. Watson ${ }^{2}$, Hasnaa E. Jalou ${ }^{1}$, Sangeeta Chakravorty ${ }^{3}$, \\ Kieren J. Mather ${ }^{4}$ and Silva A. Arslanian ${ }^{3}$
}

'Department of Pediatrics, Indiana University School of Medicine, Indianapolis, IN, United States, ${ }^{2}$ Department of Pediatrics, University of Louisville School of Medicine, Louisville, KY, United States, ${ }^{3}$ Department of Pediatrics, University of Pittsburgh Medical Center, Pittsburgh, PA, United States, ${ }^{4}$ Department of Medicine, Indiana University School of Medicine, Indianapolis, IN, United States

OPEN ACCESS

Edited by: Babak Mokhlesi, University of Chicago,

United States

Reviewed by:

Licio A. Velloso, Universidade Estadual

de Campinas, Brazil

Katie O'Sullivan,

University of Chicago,

United States

*Correspondence:

Tamara S. Hannon

tshannon@iu.edu

Specialty section:

This article was submitted to

Systems and Translational

Endocrinology,

a section of the journal

Frontiers in Endocrinology

Received: 26 March 2018

Accepted: 14 May 2018

Published: 01 June 2018

Citation:

Hannon TS, Watson SE, Jalou HE,

Chakravorty S, Mather KJ and Arslanian SA (2018) Characteristics of Obstructive Sleep Apnea Across the Spectrum of Glucose Tolerance in Obese Adolescents.

Front. Endocrinol. 9:281.

doi: 10.3389/fendo.2018.00281
Background: It is not known if dysglycemia and sleep-disordered breathing are linked in adolescents, as in adults.

Objective: To perform a pilot study evaluating measures of sleep-disordered breathing across the spectrum of glucose tolerance in obese adolescents. We hypothesized that dysglycemia would be associated with sleep-disordered breathing.

Participants/methods: This was a prospective, cross-sectional clinical pilot study that included 57 adolescents [body mass index (BMI) $38.9 \pm 8.4 \mathrm{~kg} / \mathrm{m}^{2}$ ] aged $12-18$ years $(14.5 \pm 1.6)$ with normal glucose tolerance (NGT), or dysglycemia [impaired glucose tolerance (IGT) or type 2 diabetes (T2D)].

Measures: Anthropometrics, overnight polysomnogram, and oral glucose tolerance tests were performed. Participant characteristics and outcome measures were compared by glucose tolerance status. Correlational analyses were conducted to assess the associations between variables of interest.

Results: Participants with dysglycemia $(n=21)$ were not different from those with NGT $(n=36)$ for BMI, waist circumference, body fat, or sleep characteristics. Nocturnal oxygen desaturation was associated with higher BMI $(r=-0.334, p=0.012)$. The apneahypopnea index (AHI) was not associated with physical and metabolic parameters. Although participants with dysglycemia tended to have higher AHIs (median 3.2, 2.2, and 1.6 events/h for T2D, IGT, and NGT, respectively), there was not a linear relationship between measures of glycemia and AHI.

Conclusion: Further study with a larger proportion of youth with prediabetes and T2D is necessary to determine whether evaluation for sleep-disordered breathing is uniformly warranted.

Keywords: obesity, prediabetes, pediatric, sleep-disordered breathing, apnea, insulin sensitivity 


\section{INTRODUCTION}

Prediabetes and type 2 diabetes (T2D) are strongly associated with obstructive sleep apnea (OSA) in adults (1). In the Look AHEAD study, $>80 \%$ of overweight adult participants with T2D were found to have OSA on screening polysomnogram (PSG) (2). In adults, OSA is linked with higher hemoglobin A1C values across the range of glucose tolerance (3), and treatment of OSA has been associated with improvement in blood glucose control $(4,5)$. In youth, it is unknown if prediabetes and/or T2D and OSA or sleep-disordered breathing are linked, as few similar studies have been performed (6). In this pilot study, we sought to evaluate if sleep-disordered breathing is prevalent in obese adolescents with dysglycemia, and whether sleep-disordered breathing is associated with blood glucose measures. This is important to study in adolescents because: (1) adolescents have physiologic insulin resistance which increases risk for dysglycemia and development of prediabetes and T2D (7); (2) adolescents with obesity and T2D have particularly poor health outcomes $(8,9)$; and (3) longer exposure to T2D and sleep-disordered breathing may further exacerbate these poor health outcomes.

The primary objective of this pilot study was (a) to evaluate PSG-derived measures of sleep-disordered breathing across the spectrum of glucose tolerance in obese adolescents. We utilized oral glucose tolerance tests (OGTT) to categorize youth as having normal glucose tolerance (NGT), or dysglycemia [OGTT values consistent with prediabetes defined as impaired fasting glucose (IFG) and/or impaired glucose tolerance (IGT), and T2D], and (b) to examine the associations between OGTT-derived measures of glucose tolerance, insulin sensitivity, and insulin secretion and PSG-derived measures of OSA. We hypothesized that obese youth with dysglycemia would have more characteristics of OSA than obese youth with NGT.

\section{MATERIALS AND METHODS}

This cross-sectional study was approved by the University of Pittsburgh and Indiana University Institutional Review Boards and performed in the Pediatric Clinical and Translational Research Center (Children's Hospital of Pittsburgh) and the Indiana Clinical Research Center with collaboration from the clinical sleep centers at these institutions. Informed and written consent was obtained from a parent/guardian, and assent was obtained from participants. A convenience sample of eligible subjects referred to outpatient weight management or endocrinology clinics for obesity, prediabetes, or T2D, and who also reported snoring were approached for participation. Eligibility criteria were 12 - to 18-year-old male or female adolescents (Tanner stage $>1$ ) of any race with body mass index $(\mathrm{BMI}) \geq 95$ th percentile. Exclusion criteria included diagnosis of type 1 diabetes, current tonsillar hypertrophy, chronic disease, or medications that may interfere with sleep, endocrine function or glucose regulation, syndromic obesity, chronic upper or lower airway disease, smoking, or current upper respiratory tract infection. Participants treated with either metformin and/or lifestyle recommendations were eligible, after discontinuing metformin/exercise treatment for $48 \mathrm{~h}$ before study. If there was a previous diagnosis of T2D, duration was less than 2 years for all participants. Ninety-six patients were screened for the study, and 57 participants enrolled and completed study visits after informed consent/assent was obtained. Data for part of this study cohort have been previously published (10-12).

\section{Study Procedures and Assays}

All participants had an examination by a pediatric endocrinologist that included assessment of pubertal development, anthropometric measurements, and 53/57 had body composition by dual-energy X-ray absorptiometry ( 4 had body weights greater than machine limits). A fasting laboratory evaluation including $\mathrm{HbA1C}$, glucose, and insulin, and 2-h OGTT (1.75 g/kg, maximum 75 g; glucose and insulin at $-15,0,+15,+30,+60,+90$, and +120 min time points) was performed. Fifty-three of fifty-seven participants completed the OGTT without complications. The remaining participants had minor complications, usually related to loss of intravenous access, which prohibited frequent blood sampling or reduced sample volume. Plasma glucose was measured by the glucose oxidase method (Pittsburg) and the glucose hexokinase method (Indianapolis). Samples were re-measured in Indianapolis using the glucose hexokinase method when available. Plasma insulin was determined by Beckman Coulter DXI 800 using a chemiluminescent sandwich assay (CV 6\%).

\section{Polysomnograms}

Overnight PSGs were performed in the sleep lab either the night immediately preceding the OGTT or the night immediately following the OGTT. Due to scheduling issues, it was not possible to conduct all studies in the same order. There were no differences in outcomes based on timing of the OGTT. Data were recorded using either Sensormedics Somnostar Pro version 7.2 or the Sandman Elite 9.1 sleep diagnostic software, and applying the following EEG montage: F3M2, F4M1, C3M2, C4M1, O2M1, O1M2, L-EOG, R-EOG, chin EMG, limb EMG, and the following cardiorespiratory parameters: $\mathrm{SpO}_{2}$ and pulse (Masimo), ETCO2 (Microstream NPB 70 and Capnograph Sleep by BCI), nasal pressure, airflow (nasal or oral thermistor), thoracic and abdominal excursion (uncalibrated respirator inductance plethysmography), pulse, and ECG. The PSG data were interpreted by one of two sleep Board-certified co-investigators specific to the site where the PSG was performed, who had no knowledge of the participants' metabolic status. Sleep architecture and respiratory disturbances including the minimum percent oxyhemoglobin saturation $\left(\mathrm{SpO}_{2}\right)$ by pulse oximetry, arousal events per hour (sleep fragmentation), and the apnea-hypopnea index (AHI, total number of central and obstructive apnea and hypopnea events per $1 \mathrm{~h}$ of sleep), were hand-scored utilizing pediatric criteria and calculated following the AASM manual for scoring guidelines (13). Obstructive apneas were scored for a drop in the peak flow signal by $\geq 90 \%$ of the pre-event baseline using an oral thermal sensor lasting $\geq 90 \%$ for the duration of at least two breaths during baseline breathing and associated with the presence of respiratory efforts throughout the entire period of the absent flow. Hypopneas were scored for a drop by $\geq 30 \%$ of the pre-event baseline using nasal pressure lasting $\geq$ two breaths duration in association with either $\geq 3 \%$ oxygen desaturation 
from the pre-event baseline or the event is associated with an arousal. Nocturnal hypoxia is defined as the time spent with $\mathrm{SpO}_{2}$ less than $90 \%$ for more than $5 \mathrm{~min}$.

\section{Calculations}

Insulin sensitivity was estimated using inverse fasting insulin (14). Insulin secretion was expressed as the ratio of the incremental response of insulin to glucose at $30 \mathrm{~min}$ during the OGTT [insulinogenic index (IGI), $\Delta \mathrm{I}_{0-30} / \Delta \mathrm{G}_{0-30}$, i.e., the IGI (15). Insulin secretion in relation to insulin sensitivity (oral disposition index) was calculated as $\left(\Delta \mathrm{I}_{0-30} / \Delta \mathrm{G}_{0-30} \times 1 /\right.$ fasting insulin) (15). OGTT glucose and insulin areas under the curve (AUC) were calculated using the trapezoidal method.

\section{Statistical Analysis}

Demographic and clinical characteristics of the cohort were summarized, and participants were compared by glucose tolerance status [NGT or having dysglycemia (IFG, IGT, or T2D)]. Dysglycemia was defined as having IFG or IGT using American Diabetes Association (ADA) criteria (16). T2D was defined using ADA criteria for OGTT results (16). Data were log-transformed when not normally distributed. Scatter plots were used to examine the relationships between variables of interest for the entire study cohort, and for NGT and dysglycemia groups. Non-parametric tests for independent samples were performed using KruskalWallis one-way ANOVA. Spearman's correlation coefficients were used to quantify linear correlations, as data were not uniformly distributed for the cohort. Given the pilot nature of the study, we did not perform a pre-study sample-size calculation to address whether or not OSA was related to prediabetes or T2D in adolescent youth. Post hoc power analysis showed that with the current sample size, we had $80 \%$ power to detect correlation coefficients greater than 0.37 (17). Considering the preliminary nature of the investigation, we did not perform multiplicity adjustment. $p$ Values $<0.05$ were considered statistically significant. All analyses were implemented using SPSS software (Version 24).

\section{RESULTS}

Characteristics of the participants are reported in Table $\mathbf{1}$. Thirty-six (63.2\%) had OGTT results consistent with NGT; 21 had dysglycemia on OGTT [IFG $(n=5)$, IGT $(n=11)$, both

TABLE 1 | Characteristics of the study participants.

\begin{tabular}{|c|c|c|c|c|}
\hline & Total study population & Normoglycemic & Dysglycemic & $p$ Value \\
\hline Total (\%) & $57(100)$ & $36(63.2)$ & $21(36.8)$ & \\
\hline Age, years (SD) & $14.5 \pm 1.6$ & $14.5 \pm 1.6$ & $14.2 \pm 1.7$ & 0.50 \\
\hline \multicolumn{5}{|l|}{ Sex } \\
\hline Female & $30(52.6 \%)$ & $15(41.7 \%)$ & $15(71.4 \%)$ & 0.03 \\
\hline Male & $27(47.4 \%)$ & $21(53.3 \%)$ & $6(28.6 \%)$ & \\
\hline \multicolumn{5}{|l|}{ Race } \\
\hline White & 29 (50.9\%) & 19 (52.8\%) & $10(47.6 \%)$ & 0.66 \\
\hline Black & 27 (47.4\%) & $16(44.4 \%)$ & $11(52.4 \%)$ & \\
\hline Mixed race & $1(1.8 \%)$ & $1(2.8 \%)$ & $0(0 \%)$ & \\
\hline Body mass index (BMl) $\left(\mathrm{kg} / \mathrm{m}^{2}\right)$ & $38.9 \pm 8.4(35.0,28.4-61.6)$ & $38.3 \pm 8.4(34.8,28.4-61.6)$ & $39.8 \pm 8.5(35.5,28.7-57.1)$ & 0.53 \\
\hline BMI SDS & $3.88 \pm 1.50(3.43,1.80-8.31)$ & $3.83 \pm 1.57(3.35,1.80-8.31)$ & $3.95 \pm 1.39(3.80,2.04-6.43)$ & 0.77 \\
\hline Waist circumference (cm) & $113.8 \pm 17.8(109.0,78.1-155.0)$ & $115.3 \pm 16.6(111.6,91.4-155.0)$ & $111.1 \pm 19.8(106.0,78.1-149.0)$ & 0.39 \\
\hline Body fat $(\%)$ & $46.4 \pm 6.1(n=53)(46.3,36.7-58.5)$ & $45.3 \pm 5.7(n=32)(44.7,36.8-58.5)$ & $48.9 \pm 6.1(48.9,36.7-57.2)$ & 0.035 \\
\hline \multicolumn{5}{|l|}{ Laboratory characteristics } \\
\hline $\mathrm{HbA1c}(\%)$ & $5.8 \pm 1.3(5.4,4.5-12.0)$ & $5.5 \pm 0.8(5.4,4.5-9.6)$ & $6.3 \pm 1.8(5.9,5.0-12.0)$ & 0.014 \\
\hline Fasting glucose (mg/dL) & $98.3 \pm 7.4(91.5,74-231)$ & $88.6 \pm 6.5(89.3,74-99)$ & $114.9 \pm 37.4(101.0,79-231)$ & $<0.001$ \\
\hline OGTT 2-h glucose (mg/dL) & $143 \pm 52(n=56)(128,89-332)$ & $118.8 \pm 13.7(122,89-138)$ & $187.2 \pm 66.5(157.5,98-332)$ & $<0.001$ \\
\hline 1/Fasting insulin $(\mu \mathrm{U} / \mathrm{mL})$ & $\begin{array}{c}0.0421 \pm 0.0210(n=52) \\
(0.0385,0.0100-0.0900)\end{array}$ & $\begin{array}{c}0.0481 \pm 0.0210(n=34) \\
(0.0446,0.0200-0.0900)\end{array}$ & $\begin{array}{c}0.0307 \pm 0.0159(n=18) \\
(0.0321,0.0100-0.0700)\end{array}$ & 0.003 \\
\hline Insulinogenic index & $\begin{array}{c}3.79 \pm 2.64(n=51) \\
(3.01,0.30-12.3)\end{array}$ & $\begin{array}{c}3.60 \pm 2.0(n=33) \\
(3.27,0.36-7.83)\end{array}$ & $\begin{array}{c}4.14 \pm 3.57(n=18) \\
(2.63,0.30-12.26)\end{array}$ & 0.95 \\
\hline Oral disposition index & $13.6 \pm 10.0(n=51)(11.8,0.81-56.6)$ & $15.4 \pm 10.3(n=33)(13.9,2.5-56.6)$ & $10.2 \pm 8.6(n=18)(7.0,0.8-34.5)$ & 0.022 \\
\hline \multicolumn{5}{|l|}{ Sleep characteristics } \\
\hline Polysomnogram sleep time, min & $411 \pm 53(415,233-494)$ & $406 \pm 53(415,233-478)$ & $419 \pm 54(414,314-494)$ & 0.61 \\
\hline Sleep latency, min & $15.5 \pm 14.4(12.0,<1.0-67.0)$ & $14.8 \pm 13.6(12.3,1.0-67.0)$ & $16.6 \pm 16.0(12.0,<1.0-54.0)$ & 0.93 \\
\hline REM sleep, $\%$ of total & $18.9 \pm 5.2$ & $18.9 \pm 5.5$ & $18.9 \pm 4.6$ & 0.99 \\
\hline Slow wave sleep, \% of total & $19.4 \pm 7.1$ & $20.0 \pm 6.9$ & $18.3 \pm 7.6$ & 0.42 \\
\hline Apnea-hypopnea Index (AHI), events/h & $4.7 \pm 8.1(2.2,0.0-50.4)$ & $3.3 \pm 4.1(1.6,0.0-20.0)$ & $7.0 \pm 11.0(2.9,0.0-50.4)$ & 0.19 \\
\hline $\mathrm{AHI}<1$ & $17(29.8)$ & $12(33.3)$ & $5(23.8)$ & \\
\hline Mild obstructive sleep apnea (OSA); & $24(42.1)$ & $17(47.2)$ & 7 (33.3) & \\
\hline \multicolumn{5}{|l|}{$\mathrm{AHI} \geq 1$ to $<5$} \\
\hline Moderate OSA; $\mathrm{AHI} \geq 5$ to $<10$ & $8(14.0)$ & $4(11.1)$ & $4(19.0)$ & \\
\hline Severe OSA; $\mathrm{AHI} \geq 10$ & $8(14.0)$ & $3(8.3)$ & $5(23.8)$ & \\
\hline Adult OSA cutoff met, $\mathrm{AHI}>5, n(\%)$ & $16(28.1)$ & $7(19.4)$ & $9(42.9)$ & $0.07^{a}$ \\
\hline Arousal index, events/h & $9.7 \pm 6.3(8.4,2.0-39.2)$ & $9.4 \pm 4.7(8.7,3.5-25.3)$ & $10.3 \pm 8.8(7.9,2.0-39.2)$ & 0.67 \\
\hline Nadir $\mathrm{SpO}_{2}, \%$ & $88.6 \pm 6.5(91,58-96)$ & $90.3 \pm 4.7(92,77-96)$ & $86.0 \pm 8.4(87.0,58-94)$ & 0.06 \\
\hline
\end{tabular}

Data are means $\pm S D$ unless otherwise indicated. Median, range are given in parentheses for variables not normally distributed.

aFisher's Exact Test for the proportion with $\mathrm{AHI}>5$ in each group (normoglycemic and dysglycemic). 
IFG and IGT $(n=3)$, FPG $\geq 126 \mathrm{mg} / \mathrm{dL}(n=3)$, OGTT 2 -h glucose $\geq 200 \mathrm{mg} / \mathrm{dL}(n=5)$ ]. Participants with dysglycemia were not significantly different from those with NGT for BMI, BMI SDS, or waist circumference. Percent body fat was higher in the group with dysglycemia (Table 1). Sleep characteristics among the groups divided by glycemia categories are shown in Table 1. There were no sex- or race-related differences in sleep characteristics. Seventeen $(29.8 \%)$ had normal sleep studies with AHI $<1 ; 24(42.1 \%)$ had AHI $\geq 1$ to $<5$; 8 (14.0\%) had AHI $\geq 5$ to $<10 ; 6(10.5 \%)$ had AHI $\geq 10$ to $<15 ; 2(3.5 \%)$ had AHI $\geq 15$.

The numbers and percentages of participants meeting criteria for OSA based on the AHI (mild, 1 to $<5$ events/h; moderate, 5 to $<10$ events/h; severe, $\geq 10$ events/h) are shown in Table 1. The majority of participants had an AHI $<5$ events/h. The percentage of participants meeting criteria for any degree of OSA was $66.7 \%$ in those with normal glycemia and $76.2 \%$ in those with dysglycemia. The between-group difference was not statistically significant $(p=0.07)$. Spearman's correlation coefficients for the associations between laboratory markers of glycemia and $\beta$-cell function, and indices of sleep fragmentation and sleep-disordered breathing (arousal events per hour, AHI, and nadir $\mathrm{SpO}_{2}$ during PSG) are shown in Table 2. BMI, waist circumference, percent body fat, and laboratory measures were not associated with the arousal index or the AHI. Higher BMI, higher waist circumference, and higher fasting and 2-h glucose concentrations were associated with lower nadir nocturnal $\mathrm{SpO}_{2}$. However, there was an outlier for nadir nocturnal $\mathrm{SpO}_{2}$ ( $58 \%,>2$ SD from the mean). When the outlier was removed, the association between nadir nocturnal $\mathrm{SpO}_{2}$ and $\mathrm{BMI}$ remained $(r=-0.334, p=0.012)$, but the associations with waist circumference $(r=-0.0258, p=0.055)$, and with fasting $(r=-0.229, p=0.09)$ and 2-h glucose $(r=-0.244, p=0.07)$ were no longer significant (Figure 1).

When only participants with NGT were evaluated, lower nadir $\mathrm{SpO}_{2}$ was associated with higher BMI $(r=-0.34, p=0.04)$, higher waist circumference $(r=-0.37, p=0.03)$, lower inverse fasting insulin $(r=0.41, p=0.02)$, and IGI $(r=-0.40, p=0.02)$ (Table 3). There were no significant relationships between laboratory and sleep measures in the participants with dysglycemia (Table 4). However, among those with T2D, nadir $\mathrm{SpO}_{2}$ was significantly associated with waist circumference $(r=-0.86, p=0.007)$.

TABLE 2 | Correlation coefficients for the associations of sleep measures with physical and metabolic parameters.

\begin{tabular}{|c|c|c|c|c|c|c|c|c|c|}
\hline & $\begin{array}{l}\text { Body mass } \\
\text { index }\end{array}$ & Waist circ. & Body fat (\%) & HbA1c & Fasting glucose & 2-h Glucose & $\begin{array}{l}\text { 1/Fasting } \\
\text { insulin }\end{array}$ & $\begin{array}{l}\text { Insulinogenic } \\
\text { index }\end{array}$ & $\begin{array}{c}\text { Oral } \\
\text { disposition } \\
\text { index }\end{array}$ \\
\hline $\begin{array}{l}\text { Arousal } \\
\text { index, } \\
\text { events/h }\end{array}$ & $-0.074(0.59)$ & $-0.031(0.82)$ & $-0.164(0.26)$ & $0.151(0.28)$ & $-0.086(0.54)$ & $-0.074(0.60)$ & $0.044(0.76)$ & $-0.064(0.66)$ & $-0.094(0.52)$ \\
\hline $\begin{array}{l}\text { Apnea- } \\
\text { hypopnea } \\
\text { index, } \\
\text { events/h }\end{array}$ & $0.175(0.19)$ & $0.169(0.21)$ & $-0.037(0.79)$ & $0.044(0.74)$ & $0.184(0.17)$ & $0.156(0.25)$ & $-0.089(0.53)$ & $-0.087(0.55)$ & $-0.177(0.21)$ \\
\hline $\begin{array}{l}\text { Nadir } \\
\mathrm{SpO}_{2}, \%\end{array}$ & $-0.318(0.02)$ & $-0.263(0.048)$ & $0.081(0.56)$ & $-0.087(0.52)$ & $-0.266(0.046)$ & $-0.284(0.03)$ & $0.239(0.09)$ & $-0.056(0.69)$ & $0.068(0.64)$ \\
\hline
\end{tabular}

Data are Spearman's coefficients ( $p$ values).
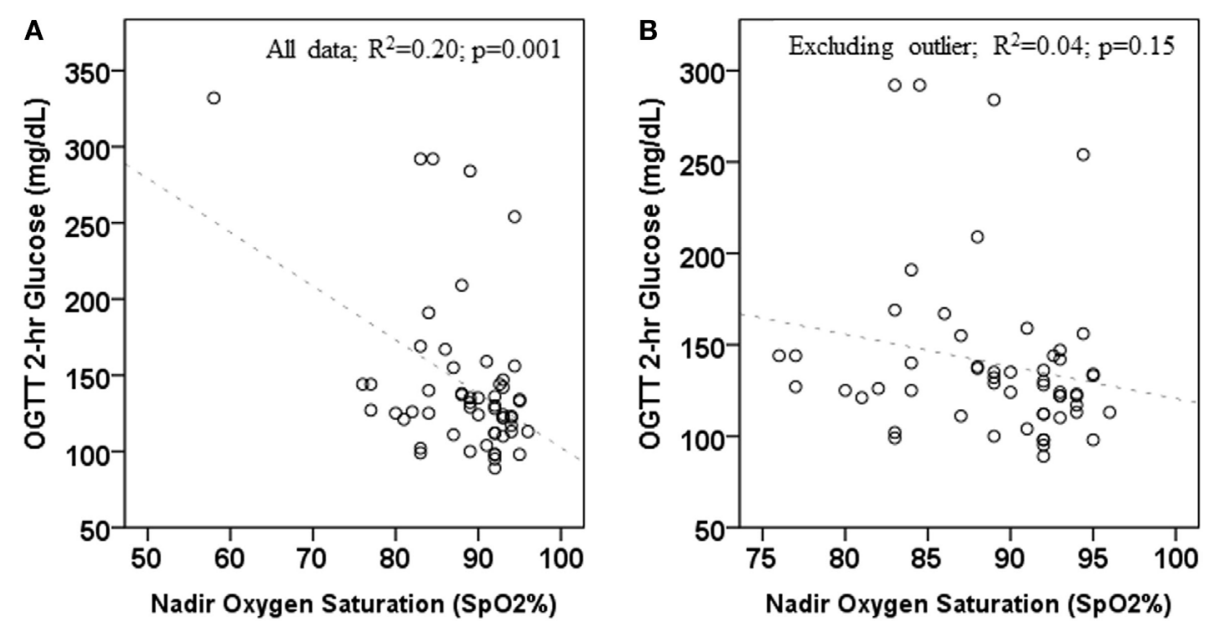

FIGURE 1 | Association between 2-h oral glucose tolerance tests (OGTT) glucose concentration and nadir oxygen saturation during polysomnogram. (A) includes all data; (B) excludes one outlier. 
TABLE 3 | Correlation coefficients for the associations of sleep measures with physical and metabolic parameters, normal glucose tolerance group only.

\begin{tabular}{|c|c|c|c|c|c|c|c|c|c|c|}
\hline & $\begin{array}{c}\text { Body mass } \\
\text { index }\end{array}$ & $\begin{array}{l}\text { Waist } \\
\text { circ. }\end{array}$ & $\begin{array}{c}\text { Body fat } \\
(\%)\end{array}$ & HbA1c & $\begin{array}{l}\text { Fasting } \\
\text { glucose }\end{array}$ & $\begin{array}{c}\text { 2-h } \\
\text { Glucose }\end{array}$ & $\begin{array}{l}\text { Glucose } \\
\text { areas under } \\
\text { the curve }\end{array}$ & $\begin{array}{l}\text { 1/Fasting } \\
\text { insulin }\end{array}$ & $\begin{array}{l}\text { Insulinogenic } \\
\text { index }\end{array}$ & $\begin{array}{c}\text { Oral } \\
\text { disposition } \\
\text { index }\end{array}$ \\
\hline $\begin{array}{l}\text { Arousal index, } \\
\text { events/h }\end{array}$ & $\begin{array}{c}-0.086 \\
(0.74)\end{array}$ & $\begin{array}{c}-0.104 \\
(0.55)\end{array}$ & $\begin{array}{l}0.062 \\
(0.74)\end{array}$ & $\begin{array}{l}0.303 \\
(0.07)\end{array}$ & $\begin{array}{l}0.034 \\
(0.84)\end{array}$ & $\begin{array}{c}-0.037 \\
(0.83)\end{array}$ & $\begin{array}{l}0.234 \\
(0.18)\end{array}$ & $\begin{array}{l}0.047 \\
(0.79)\end{array}$ & $\begin{array}{c}-0.236 \\
(0.19)\end{array}$ & $\begin{array}{c}-0.319 \\
(0.07)\end{array}$ \\
\hline $\begin{array}{l}\text { Apnea- } \\
\text { hypopnea } \\
\text { index, events/h }\end{array}$ & $\begin{array}{l}0.143 \\
(0.41)\end{array}$ & $\begin{array}{l}0.247 \\
(0.15)\end{array}$ & $\begin{array}{c}-0.064 \\
(0.73)\end{array}$ & $\begin{array}{c}-0.029 \\
(0.87)\end{array}$ & $\begin{array}{l}0.260 \\
(0.13)\end{array}$ & $\begin{array}{l}0.012 \\
(0.95)\end{array}$ & $\begin{array}{l}0.149 \\
(0.40)\end{array}$ & $\begin{array}{c}-0.198 \\
(0.26)\end{array}$ & $\begin{array}{c}-0.087 \\
(0.55)\end{array}$ & $\begin{array}{c}-0.177 \\
(0.21)\end{array}$ \\
\hline Nadir $\mathrm{SpO}_{2}, \%$ & $\begin{array}{c}-0.342 \\
(0.04)\end{array}$ & $\begin{array}{c}-0.372 \\
(0.03)\end{array}$ & $\begin{array}{l}0.151 \\
(0.40)\end{array}$ & $\begin{array}{c}-0.010 \\
(0.95)\end{array}$ & $\begin{array}{c}-0.283 \\
(0.10)\end{array}$ & $\begin{array}{c}-0.127 \\
(0.46)\end{array}$ & $\begin{array}{c}-0.064 \\
(0.72)\end{array}$ & $\begin{array}{l}0.405 \\
(0.02)\end{array}$ & $\begin{array}{c}-0.402 \\
(0.02)\end{array}$ & $\begin{array}{c}-0.143 \\
(0.43)\end{array}$ \\
\hline
\end{tabular}

Data are Spearman's coefficients ( $p$ values).

TABLE 4 | Correlation coefficients for the associations of sleep measures with physical and metabolic parameters, dysglycemic group.

\begin{tabular}{|c|c|c|c|c|c|c|c|c|c|c|}
\hline & $\begin{array}{l}\text { Body mass } \\
\text { index }\end{array}$ & $\begin{array}{l}\text { Waist } \\
\text { circ. }\end{array}$ & $\begin{array}{c}\text { Body fat } \\
\text { (\%) }\end{array}$ & HbA1c & $\begin{array}{l}\text { Fasting } \\
\text { glucose }\end{array}$ & $\begin{array}{l}\text { 2-h } \\
\text { Glucose }\end{array}$ & $\begin{array}{l}\text { Glucose } \\
\text { areas under } \\
\text { the curve }\end{array}$ & $\begin{array}{l}\text { 1/Fasting } \\
\text { insulin }\end{array}$ & $\begin{array}{l}\text { Insulinogenic } \\
\text { index }\end{array}$ & $\begin{array}{l}\text { Oral disposition } \\
\text { index }\end{array}$ \\
\hline $\begin{array}{l}\text { Arousal index, } \\
\text { events/h }\end{array}$ & $\begin{array}{c}-0.038 \\
(0.88)\end{array}$ & $\begin{array}{l}0.009 \\
(0.97)\end{array}$ & $\begin{array}{c}-0.399 \\
(0.10)\end{array}$ & $\begin{array}{l}0.046 \\
(0.86)\end{array}$ & $\begin{array}{c}-0.104 \\
(0.68)\end{array}$ & $\begin{array}{c}-0.242 \\
(0.35)\end{array}$ & $\begin{array}{c}-0.164 \\
(0.53)\end{array}$ & $\begin{array}{c}-0.076 \\
(0.77)\end{array}$ & $\begin{array}{l}0.147 \\
(0.57)\end{array}$ & $\begin{array}{l}0.201 \\
(0.44)\end{array}$ \\
\hline $\begin{array}{l}\text { Apnea- } \\
\text { hypopnea } \\
\text { index, events/h }\end{array}$ & $\begin{array}{l}0.172 \\
(0.46)\end{array}$ & $\begin{array}{l}0.172 \\
(0.46)\end{array}$ & $\begin{array}{c}-0.088 \\
(0.70)\end{array}$ & $\begin{array}{c}-0.020 \\
(0.93)\end{array}$ & $\begin{array}{c}-0.118 \\
(0.61)\end{array}$ & $\begin{array}{l}0.083 \\
(0.73)\end{array}$ & $\begin{array}{l}0.170 \\
(0.47)\end{array}$ & $\begin{array}{l}0.340 \\
(0.17)\end{array}$ & $\begin{array}{c}-0.171 \\
(0.50)\end{array}$ & $\begin{array}{l}0.059 \\
(0.82)\end{array}$ \\
\hline Nadir $\mathrm{SpO}_{2}, \%$ & $\begin{array}{c}-0.225 \\
(0.33)\end{array}$ & $\begin{array}{c}-0.331 \\
(0.14)\end{array}$ & $\begin{array}{l}0.047 \\
(0.84)\end{array}$ & $\begin{array}{c}-0.006 \\
(0.98)\end{array}$ & $\begin{array}{l}0.031 \\
(0.89)\end{array}$ & $\begin{array}{c}-0.169 \\
(0.48)\end{array}$ & $\begin{array}{c}-0.268 \\
(0.25)\end{array}$ & $\begin{array}{c}-0.369 \\
(0.13)\end{array}$ & $\begin{array}{l}0.380 \\
(0.12)\end{array}$ & $\begin{array}{l}0.157 \\
(0.53)\end{array}$ \\
\hline
\end{tabular}

Data are Spearman's coefficients (p values).

\section{DISCUSSION}

In this pilot study, we evaluated PSG-measured sleep-disordered breathing in obese adolescents with a range of glucose tolerance. The median AHI in this study was 2.2 events/h, and the majority of participants had an AHI less than 5 events/h, which is the threshold for OSA in adults (18). Although participants with dysglycemia tended to have higher AHIs (median 3.2, 2.2, and 1.6 events/h for T2D, prediabetes, and NGT, respectively), there was not a linear relationship between measures of glycemia and AHI. The percentage of participants meeting criteria for any degree of OSA (AHI greater than or equal to 1 events/h) was $66.7 \%$ in those with normal glycemia versus $76.2 \%$ in those with dysglycemia, although this did not meet criteria for statistical significance $(p=0.07)$. Individuals in each category of glucose tolerance had PSG evaluations consistent with OSA, with wide variability. Higher BMI, higher waist circumference, and greater insulin resistance (lower inverse fasting insulin) were associated with lower nadir $\mathrm{SpO}_{2}$ among participants with NGT. Although our hypothesis that youth with dysglycemia would have higher AHI than obese youth with NGT was not verified in this study, our results suggest that a study with a greater proportion of youth with dysglycemia and T2D is warranted and should be pursued through a larger network of clinical sites.

An association with nocturnal hypoxia and hyperglycemia has been shown in adult T2D studies, where greater levels of oxygen desaturation or even relatively mild intermittent hypoxemia were associated with poorer glycemic control (19-23). Also, improving glycemic control in adults with T2D via a pharmacological intervention has been associated with a decrease in nocturnal oxygen desaturation (24). The mechanisms of this complex relationship are not yet completely understood, but central, autonomic, and inflammatory mechanisms have been implicated (25-27). Rodent studies have shown that circulating catecholamines act upon $\alpha$-adrenoreceptors, leading to hyperglycemia and glucose intolerance when intermittent hypoxia is imposed (28).

Pediatric studies have shown that OSA measured by PSG is associated with markers of insulin resistance as measured by fasting insulin and glucose (HOMA-IR) $(29,30)$, OGTT (10), and intravenous glucose tolerance testing (31). However, pediatric studies examining the relationship between OSA and dysglycemia have had mixed results. Verhulst et al. showed the mean nocturnal $\mathrm{SpO}_{2}$ was independently correlated with OGTT glucose area under the curve in lean and obese youth aged 6-16 years (32). However, in the Cleveland Children's Sleep and Health Study, oxygen desaturation was not associated with OGTT-stimulated glucose concentrations in a community-based cohort of lean and obese adolescents ( $n=270$; mean age 13.7 years; $41 \%$ with BMI $\geq 85$ th percentile) (30). The fact that most of the participants were not obese in this previous study may contribute to the different outcomes (30). de Sousa et al. compared PSG variables and OGTT-derived measures of glucose tolerance in obese white adolescents with polycystic ovary syndrome (PCOS, $n=31$ ) to those of healthy control females $(n=19)$ (33). This study found a positive correlation between AHI and HOMA-IR $(r=0.21$, $p=0.01$ ), but no association between PSG parameters and OGTT glucose measures. The same group studied changes in PSG variables and OGTT glucose measures in obese adolescents 
treated for PCOS longitudinally ( $n=15$, mean age $15.3 \pm 1.2 \mathrm{y}$, $28 \pm 6$ months between evaluations) (34). Body composition, PSG variables, and OGTT-derived measures of glucose metabolism were unchanged from baseline. Koren et al. also found no association between measures of sleep-disordered breathing and OGTT measures (35). Similar to our study, participants were all obese $(n=62$, mean age 14.4 years, range $8-17.5$; mean BMI $37 \mathrm{~kg} / \mathrm{m}^{2}$ ) with a range of glucose tolerance. The age range was broader in this previous study, and the range of minimum $\mathrm{SaO}_{2}$ values was greater in our study.

Shalitin et al. evaluated obese children and adolescents with and without T2D ( $n=11, n=30$, respectively) with PSG and fasting laboratory tests (6). There were no between-group differences in $\mathrm{AHI}>5 / \mathrm{h}$. The percentage of participants with $\mathrm{AHI}>5 / \mathrm{h}$ was $45 \%$ in participants with T2D, 25\% in obese participants with IGT, and $18 \%$ in obese participants with NGT. Similarly, our study found: AHI $>5 / \mathrm{h}$ was $43 \%$ in participants with dysglycemia and $19 \%$ in obese participants without dysglycemia. In both studies, participants with dysglycemia were more likely to have AHI meeting the criteria for OSA; however, between-group differences were not statistically significant in either study. Both studies lacked sufficient participants to adequately test the hypothesis that OSA occurs more frequently in obese adolescents with dysglycemia. It may be that obese youth are at risk for both sleep-disordered breathing and T2D, but the associations are weaker in youth than in adults. It could also be that the pathophysiology linking T2D and hypoxia is much more prevalent in older adults as compared with adolescents. A larger study in adolescents will be required to determine whether or not these speculations are accurate.

This study has limitations that warrant consideration. Participants who reported snoring were recruited from obesity referral clinics, limiting the generalizability to the broader adolescent population. Participants treated with either metformin and/ or lifestyle recommendations were eligible, after discontinuing treatment for a short period of time. Previous treatment may have influenced findings in this study. The study was performed in two locations due to the principal investigator relocating, and PSGs were read and evaluated by two sleep investigators without crosscalibrations. However, the same OGTT and PSG protocol was utilized in both locations. To minimize participant burden and enhance enrollment and participation, we opted for OGTT evaluations in lieu of more invasive glucose clamp studies. Measures often performed in adult populations, including neck circumference and level of crowding of oropharynx, were not performed. Sleep data including the percentage of time spent in REM and slow wave sleep and the percent of sleep time below $90 \%$ oxygen saturation were not uniformly available. Also, children with a history of tonsillectomy, which is a treatment for OSA in children, were not excluded. The data were not normally distributed, which was expected for glucose measures given the objective of the study. However, considering the preliminary nature of this investigation, we included all of the available data from all participants. There was a predominance of females in the dysglycemia group, as dysglycemia is more commonly occurs in female versus male adolescents. As males are more likely to have sleep-disordered breathing, evidence of sleep-disordered breathing in obese adolescents with dysglycemia could be underestimated in this setting. It must be noted that a larger sample size is required to provide a definitive answer to the question of whether or not OSA is related to dysglycemia in adolescents. Given the nature of this pilot study, an adequate sample-size calculation was not performed at the onset. Perhaps with a larger study, including more participants with T2D, sleep-disordered breathing would be seen more predominantly.

Strengths of the study include a strong rationale, given the epidemiological prevalence of OSA in obese adults and the high percentage of adults with both T2D and OSA, and the lack of previous studies in obese adolescents. The inclusion of only obese pubertal patients aged 12 years and up is of particular value given the differences in glucose metabolism in pre-pubertal and adolescent patients (7). The mean age of diagnosis of T2D in youth is 14 years (36); thus, our cohort is representative of an appropriate population for evaluation of diabetes risk markers.

In conclusion, although we did not confirm the hypothesis that obese youth with dysglycemia have more characteristics of OSA than obese youth with NGT in this pilot study, we have further added to the literature on adolescent obesity, dysglycemia, and sleep characteristics. A larger study involving a network of clinical research sites is warranted to further understand the relationship between sleep-disordered breathing and dysglycemia in obese adolescents, especially since two pediatric studies have now shown a greater proportion of OSA in obese youth with dysglycemia versus NGT. Further study with a larger proportion of youth with prediabetes and T2D will also be necessary to determine whether evaluation for sleep-disordered breathing is uniformly warranted.

\section{ETHICS STATEMENT}

This study was approved by the University of Pittsburgh and Indiana University Institutional Review Boards and performed in the Pediatric Clinical and Translational Research Center (Children's Hospital of Pittsburgh) and the Indiana Clinical Research Center with collaboration from the clinical sleep centers at these institutions. All participants and their parent (guardian) gave informed consent before participating.

\section{AUTHOR CONTRIBUTIONS}

$\mathrm{TH}$ wrote the draft of the manuscript. SW collected data and performed research procedures. HJ interpreted data. SC interpreted data. KM provided key manuscript edits and mentoring. SA provided key manuscript edits and mentoring. No honorarium, grant, or other form of payment was given to anyone to produce the manuscript. There are no prior publications or current submissions to other journals with overlapping information.

\section{FUNDING}

This work was supported by: NIH R03HD057532 (TH), Indiana University Purdue University Signature Center Grant Initiative (TH), NIDDK of the National Institutes of Health under award number T32DK065549 (SW), the Indiana Clinical and Translational Sciences Institute funded by NIH UL1TR001108, and the University of Pittsburgh Clinical and Translational Science Institute funded by NIH UL1TR001857. 


\section{REFERENCES}

1. Doumit J, Prasad B. Sleep apnea in type 2 diabetes. Diabetes Spectr (2016) 29(1):14-9. doi:10.2337/diaspect.29.1.14

2. Foster GD, Sanders MH, Millman R, Zammit G, Borradaile KE, Newman AB, et al. Obstructive sleep apnea among obese patients with type 2 diabetes. Diabetes Care (2009) 32(6):1017-9. doi:10.2337/dc08-1776

3. Tamura A, Kawano Y, Watanabe T, Kadota J. Obstructive sleep apnea increases hemoglobin A1c levels regardless of glucose tolerance status. Sleep Med (2012) 13(8):1050-5. doi:10.1016/j.sleep.2012.04.007

4. Leong WB, Banerjee D, Nolen M, Adab P, Thomas GN, Taheri S. Hypoxemia and glycemic control in type 2 diabetes mellitus with extreme obesity. J Clin Endocrinol Metab (2014) 99(9):E1650-4. doi:10.1210/jc.2014-1260

5. Guest JF, Panca M, Sladkevicius E, Taheri S, Stradling J. Clinical outcomes and cost-effectiveness of continuous positive airway pressure to manage obstructive sleep apnea in patients with type 2 diabetes in the U.K. Diabetes Care (2014) 37(5):1263-71. doi:10.2337/dc13-2539

6. Shalitin S, Tauman R, Meyerovitch J, Sivan Y. Are frequency and severity of sleep-disordered breathing in obese children and youth with and without type 2 diabetes mellitus different? Acta Diabetol (2014) 51(5):757-64. doi:10.1007/ s00592-014-0583-1

7. Hannon TS, Janosky J, Arslanian SA. Longitudinal study of physiologic insulin resistance and metabolic changes of puberty. Pediatr Res (2006) 60(6):759-63. doi:10.1203/01.pdr.0000246097.73031.27

8. Nadeau KJ, Anderson BJ, Berg EG, Chiang JL, Chou H, Copeland KC, et al. Youth-onset type 2 diabetes consensus report: current status, challenges, and priorities. Diabetes Care (2016) 39(9):1635-42. doi:10.2337/dc16-1066

9. Zeitler P, Hirst K, Pyle L, Linder B, Copeland K, Arslanian S, et al. A clinical trial to maintain glycemic control in youth with type 2 diabetes. $N$ Engl J Med (2012) 366(24):2247-56. doi:10.1056/NEJMoa1109333

10. Hannon TS, Lee S, Chakravorty S, Lin Y, Arslanian SA. Sleep-disordered breathing in obese adolescents is associated with visceral adiposity and markers of insulin resistance. Int J Pediatr Obes (2011) 6(2):157-60. doi:10.3109/17477166.2010.482156

11. Hannon TS, Rofey DL, Ryan CM, Clapper DA, Chakravorty S, Arslanian SA. Relationships among obstructive sleep apnea, anthropometric measures, and neurocognitive functioning in adolescents with severe obesity. J Pediatr (2012) 160(5):732-5. doi:10.1016/j.jpeds.2011.10.029

12. Hannon TS, Tu W, Watson SE, Jalou H, Chakravorty S, Arslanian SA. Morning blood pressure is associated with sleep quality in obese adolescents. J Pediatr (2014) 164(2):313-7. doi:10.1016/j.jpeds.2013.10.011

13. Iber C, Ancoli-Israel S, Chesson A, Quan S. American Academy of Sleep Medicine. The AASM Manual for the Scoring of Sleep and Associated Events: Rules, Terminology, and Technical Specifications. Westchester, IL: American Academy of Sleep Medicine (2007).

14. George L, Bacha F, Lee S, Tfayli H, Andreatta E, Arslanian S. Surrogate estimates of insulin sensitivity in obese youth along the spectrum of glucose tolerance from normal to prediabetes to diabetes. J Clin Endocrinol Metab (2011) 96(7):2136-45. doi:10.1210/jc.2010-2813

15. Sjaarda LG, Bacha F, Lee S, Tfayli H, Andreatta E, Arslanian S. Oral disposition index in obese youth from normal to prediabetes to diabetes: relationship to clamp disposition index. JPediatr (2012) 161(1):51-7. doi:10.1016/j. jpeds.2011.12.050

16. American Diabetes Association. (2) Classification and diagnosis of diabetes. Diabetes Care (2015) 38(Supplement 1):S8-16. doi:10.2337/dc15-S005

17. Hulley SB, Cummings SR, Browner WS, Grady D, Newman TB. Appendix 6C. In: Sonya S, Nancy W, editors. Designing Clinical Research: An Epidemiologic Approach. 4th ed. Philadelphia, PA: Lippincott Williams \& Wilkins (2013). 79 p.

18. Morton S, Rosen C, Larkin E, Tishler P, Aylor J, Redline S. Predictors of sleep-disordered breathing in children with a history of tonsillectomy and/or adenoidectomy. Sleep (2001) 24(7):823-9. doi:10.1093/sleep/24.7.823

19. Rusu A, Bala CG, Craciun AE, Roman G. HbAlc levels are associated with severity of hypoxemia and not with apnea hypopnea index in patients with type 2 diabetes: results from a cross-sectional study. J Diabetes (2016) 9(6):555-61. doi:10.1111/1753-0407.12452

20. Lecube A, Sampol G, Hernandez C, Romero O, Ciudin A, Simo R. Characterization of sleep breathing pattern in patients with type 2 diabetes: sweet sleep study. PLoS One (2015) 10(3):e0119073. doi:10.1371/journal. pone.0119073

21. Muraki I, Tanigawa T, Yamagishi K, Sakurai S, Ohira T, Imano H, et al. Nocturnal intermittent hypoxia and the development of type 2 diabetes: the circulatory risk in communities study (CIRCS). Diabetologia (2010) 53(3):481-8. doi:10.1007/s00125-009-1616-0

22. Stamatakis K, Sanders MH, Caffo B, Resnick HE, Gottlieb DJ, Mehra R, et al. Fasting glycemia in sleep disordered breathing: lowering the threshold on oxyhemoglobin desaturation. Sleep (2008) 31(7):1018-24.

23. Hui P, Zhao L, Xie Y, Wei X, Ma W, Wang J, et al. Nocturnal hypoxemia causes hyperglycemia in patients with obstructive sleep apnea and type 2 diabetes mellitus. Am J Med Sci (2016) 351(2):160-8. doi:10.1016/j.amjms.2015.12.002

24. Lecube A, Ciudin A, Sampol G, Valladares S, Hernandez C, Simo R. Effect of glycemic control on nocturnal arterial oxygen saturation: a case-control study in type 2 diabetic patients. J Diabetes (2015) 7(1):133-8. doi:10.1111/1753-0407.12197

25. Rajan P, Greenberg H. Obstructive sleep apnea as a risk factor for type 2 diabetes mellitus. Nat Sci Sleep (2015) 7:113-25. doi:10.2147/NSS.S90835

26. Drager LF, Polotsky VY, O’DonnellCP, CravoSL, Lorenzi-Filho G, MachadoBH. Translational approaches to understanding metabolic dysfunction and cardiovascular consequences of obstructive sleep apnea. Am J Physiol Heart Circ Physiol (2015) 309(7):H1101-11. doi:10.1152/ajpheart.00094.2015

27. Cheng L, Khoo MC. Modeling the autonomic and metabolic effects of obstructive sleep apnea: a simulation study. Front Physiol (2011) 2:111. doi:10.3389/fphys.2011.00111

28. Jun JC, Shin MK, Devera R, Yao Q, Mesarwi O, Bevans-Fonti S, et al. Intermittent hypoxia-induced glucose intolerance is abolished by alphaadrenergic blockade or adrenal medullectomy. Am JPhysiol Endocrinol Metab (2014) 307(11):E1073-83. doi:10.1152/ajpendo.00373.2014

29. Bhushan B, Maddalozzo J, Sheldon SH, Haymond S, Rychlik K, Lales GC, et al. Metabolic alterations in children with obstructive sleep apnea. Int J Pediatr Otorhinolaryngol (2014) 78(5):854-9. doi:10.1016/j.ijporl.2014.02.028

30. Redline S, Storfer-Isser A, Rosen CL, Johnson NL, Kirchner HL, Emancipator J, et al. Association between metabolic syndrome and sleep-disordered breathing in adolescents. Am J Respir Crit Care Med (2007) 176(4):401-8. doi:10.1164/ rccm.200703-375OC

31. Lesser DJ, Bhatia R, Tran WH, Oliveira F, Ortega R, Keens TG, et al. Sleep fragmentation and intermittent hypoxemia are associated with decreased insulin sensitivity in obese adolescent Latino males. Pediatr Res (2012) 72(3):293-8. doi: $10.1038 /$ pr.2012.73

32. Verhulst SL, Schrauwen N, Haentjens D, Rooman RP, Van Gaal L, De Backer WA et al. Sleep-disordered breathing and the metabolic syndrome in overweight and obese children and adolescents. J Pediatr (2007) 150(6):608-12. doi:10.1016/j.jpeds.2007.01.051

33. deSousaG,SchluterB,MenkeT,TrowitzschE,AndlerW,ReinehrT.Relationships between polysomnographic variables, parameters of glucose metabolism, and serum androgens in obese adolescents with polycystic ovarian syndrome. J Sleep Res (2011) 20(3):472-8. doi:10.1111/j.1365-2869.2010.00902.x

34. de Sousa G, Schluter B, Menke T, Trowitzsch E, Andler W, Reinehr T. Longitudinal analyses of polysomnographic variables, serum androgens, and parameters of glucose metabolism in obese adolescents with polycystic ovarian syndrome. Sleep Breath (2012) 16(4):1139-46. doi:10.1007/s11325-011-0620-z

35. Koren D, Levitt Katz LE, Brar PC, Gallagher PR, Berkowitz RI, Brooks LJ. Sleep architecture and glucose and insulin homeostasis in obese adolescents. Diabetes Care (2011) 34(11):2442-7. doi:10.2337/dc11-1093

36. Copeland KC, Zeitler P, Geffner M, Guandalini C, Higgins J, Hirst K, et al. Characteristics of adolescents and youth with recent-onset type 2 diabetes: the TODAY cohort at baseline. J Clin Endocrinol Metab (2011) 96(1):159-67. doi:10.1210/jc.2010-1642

Conflict of Interest Statement: The authors have no conflicts of interest to disclose. The study sponsor(s) had no role in (1) study design; (2) the collection, analysis, and interpretation of data; (3) the writing of the report; or (4) the decision to submit the paper for publication. TH wrote the first draft of the manuscript. No honorarium, grant, or other form of payment was given to anyone to produce the manuscript.

The reviewer KO and handling Editor declared their shared affiliation.

Copyright (c) 2018 Hannon, Watson, Jalou, Chakravorty, Mather and Arslanian. This is an open-access article distributed under the terms of the Creative Commons Attribution License (CC BY). The use, distribution or reproduction in other forums is permitted, provided the original author(s) and the copyright owner are credited and that the original publication in this journal is cited, in accordance with accepted academic practice. No use, distribution or reproduction is permitted which does not comply with these terms. 